\title{
Financial Literacy and Livelihood Nexus in Uganda: Re-Thinking the Intervention Pedagogy
}

\author{
${ }^{1}$ Mary Maurice Nalwoga Mukokoma, ${ }^{1}$ Jacinta Bwejeme, ${ }^{2}$ Mulumba Mathias, ${ }^{2}$ Kibuuka \\ Prossy, ${ }^{3}$ Regina Nakayenga \\ ${ }^{1}$ Uganda Martyrs University \\ ${ }^{2}$ CEPARD \\ ${ }^{3}$ RENA juice
}

\begin{abstract}
This paper reports results of a survey that was conducted in central Uganda to examine the effect of financial literacy on livelihood levels. Specifically, the study investigated the effect of financial knowledge, behaviour, and attitude on livelihood levels; and the mediating effect of financial systems on the link between financial behaviour and livelihood levels. Data was collected using questionnaires and semi-structured interview questions from 196 respondents. The regression results revealed that a combination of financial knowledge, attitude, behaviour, and systems significantly explains $14 \%$ of the variance in levels of livelihood (Adj. R Square =.140; Sig 0.007). This means that a change in the financial literacy level will lead to a change in livelihood levels. Of all the financial literacy dimensions, the results indicate that financial attitude significantly predicts livelihood levels $($ Beta $=0.498$, sig $=0.000)$. This implies that for livelihood levels to improve a positive financial attitude should be developed. When the mediation tests were conducted, it was clear that financial systems mediate the relationship of financial knowledge and behaviour and livelihoods (Sobel Z-Value of 2.35, P-value 0.011). Generally, a positive financial attitude and the effectiveness of a financial system play a key role in influencing livelihood levels. Thus, action based, and experiential learning pedagogies should be embedded in financial literacy training for participants to improve their livelihoods.
\end{abstract}

\section{Introduction}

Substantive research has shown that high levels of financial literacy are positively associated with improved livelihoods. Unfortunately, numerous studies have revealed low levels of financial literacy globally, regionally and nationally. A world survey conducted by Klapper et al. [19] in 2016 revealed that only $34 \%$ of adult Ugandan's were financially literate. Interventions have been undertaken to train people in financial literacy with a view to improve livelihood levels among other considerations.

Improving the financial literacy levels of citizens is a global and national concern by various stakeholders. Studies indicate that the world's most population suffers from low levels of financial literacy and that measures to remedy the problem are urgently needed [42].

Based on this reality, President Bush formed the President's advisory council on financial capability in 2008 and president Obama continued to champion the financial literacy movements. According to Messy and Monticone [25], many countries in Africa showed interest in financial literacy at national and policy levels.

In Uganda for instance, a number of initiatives have been undertaken. Department For International Development (DFID) in 2004 piloted the financial literacy education in two districts of Uganda; Mbale and Masaka. Also the Capital Markets Authority since 2003 has been running a secondary school challenge in financial matters; Private Education Network has been undertaking financial literacy with school children in Kampala, Wakiso and Kamuli; the Uganda Catholic Relief Service has attempted to foster financial literacy through selfmanaged community based lending; Centenary Bank since 2012, in partnership with International Labour Organisation (ILO) embarked on a project that seeks to empower youths with financial skills. In 2013, the Minister of Finance then, Hon. Maria Kiwanuka launched the financial literacy strategy for Uganda.

Despite the various interventions, the study by Refera et al. [36], Klapper et al. [19] found out that people's livelihoods in developing countries are very low. Also, data from the Private Sector Foundation (PSFU, 2016) indicated that $62 \%$ of Uganda's adult population demonstrates low levels of financial literacy manifested in low access to financial services, low levels of investment and wealthy creation. The key issue addressed by this article is why people's livelihood levels have remained low despite extensive financial literacy interventions. This concern was analysed by presenting evidence on the dynamic interactions between financial knowledge, behaviour, attitude, systems and livelihoods.

\section{Conceptual Understanding, Linkages and Gap}

In this section, an understanding of and linkages between financial literacy, livelihoods, financial behaviour, financial attitude, and financial systems 
as key concepts is explored. Besides this, the gap in literature has been explained.

\subsection{Financial literacy}

The definitions of financial literacy have been changing overtime. Noctor et al. [27] introduced financial literacy as "the ability to make informed judgments and to take effective decisions regarding the use and management of money". Mandell [23], on the other hand, defined it as "the ability to use knowledge and skills to manage one's financial resources effectively for lifetime financial security". Similarly, the European Commission [11] defined financial literacy as "capability of consumers and small business owners to understand retail financial products with a view to making informed financial decisions".

Sebstad et al. [38] argue that financial literacy means having the knowledge and skills to make responsible economic and financial decisions with confidence. For this article, financial literacy is conceptualised as the set of and knowledge, skills, attitude, behaviour and financial systems that allows an individual or entity to make informed and effective decisions about financial planning financial planning, wealth accumulation, savings, pensions and debt among others.

\section{Livelihoods}

Livelihoods can be defined variously. Chambers and Conway [7] defined it as ways in which people's needs are satisfied. Frankenberger [12] defined it as the family or community's ability to maintain and improve its assets, income and social well-being. Also, IFRC (2017) define it as encompassing people's capabilities, assets, income and activities required to secure the necessities of life. For this study livelihoods are defined as the ability of an individual or community to satisfy its basic needs namely; food, shelter, clothing, sanitation, education and health care [24].

Financial Behaviour is the economic conduct of an individual on monetary issues related to financial planning, wealth accumulation, debt and pension management. Dinga et al. [10] defined financial behaviour as a function of economic behaviour, monetary factors, and financial flows. Carol (2013) examined financial behaviour in a sample of 45000 youth adults and found-out that respondents with higher financial knowledge are less likely to use high cost borrowing methods, set aside savings for emergency and are more likely to plan for retirement.

Financial attitude is a psychological tendency expressed when evaluating recommended financial management practices with some degree of agreement of disagreement [35]. Generally, it is a psychological tendency to agree or disagree with adopting a particular financial practice.

Financial systems are policies and procedures used by a unit to allocate risk and resources and exercise financial control and accountability. They include recording, verification, and timely reporting of transactions that affect expenses, revenue, assets and liabilities.

The three dimensions of financial literacy have been used in this study because a number of researchers [33] have used them to measure financial literacy levels. Though Huston [14] conceptualised financial literacy as financial knowledge and its application, many studies since 2010 are considering attitude and behaviour as part of financial literacy. OECD (2013) for instance conceptualises financial literacy ad a combination of awareness, skill, attitude and behaviour required to make financial decisions and ultimately achieve financial wellbeing.

\section{The gap in literature}

Many studies have attempted to link financial literacy to decision making and financial behaviour. Indeed, the position of financial behaviour in the conceptual analysis is not clear. Some researchers conceptualise it as a dependent variable of financial literacy while others and a component of financial literacy. Very few studies have linked financial literacy to livelihoods. The few studies that have linked financial literacy to livelihood don't consider financial systems. This study was conducted to link financial literacy to livelihoods as mediated by financial systems.

\section{Materials And Methods}

A survey was conducted in the central region of Uganda where numerous financial literacy interventions have been conducted. Responses were got from 196 respondents who involved those in leadership positions and those with no leadership positions. Some leaders were purposively selected given their critical positions in society and the financial literacy information resource possessed.

Questionnaires and semi-structure interviews guides were questions to collect data. All items of the questionnaire were anchored on a five -point scale. A pilot study involving 32 respondents was conducted to establish construct validity and reliability of the instrument. The computed Cronbach alpha coefficient results for reliability analysis were all above 0.70 as recommended by Cronbach [9] and Tavako and Dennick [40]. Validity was assessed with due consideration of relevance, clarity, simplicity and ambiguity of the content. The computed validity scores were all above 0.75 as recommended by Yaghmale [43]. 


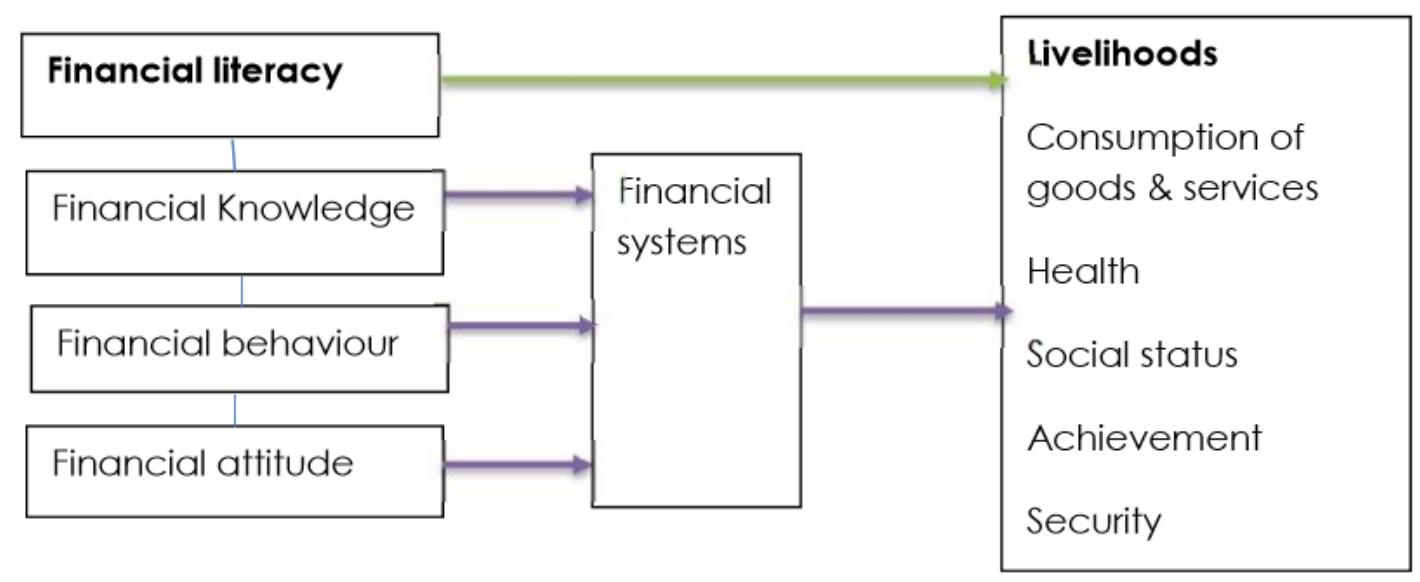

Figure 1. Conceptualisation of financial literacy and people livelihoods Source: OECD (2013) and IFRC 2017

The data was collected in three major stages. The first stage was engaging the unit (Diocese) heads leadership in an entry meeting to seek their approval and partnership in providing data, sharing findings and acting on the actions to be taken for improved livelihoods. In the entry meeting the leaders also shared the annual programmes so that appropriate timing for data collection from the different respondents could be arranged. Twenty interviews were held with the leaders who also filled questionnaires. Two sets of questionnaires were designed; one for the leaders and the other for other respondents. The second stage was to administer piloted questionnaires to respondents. Some of the respondents filled the tools themselves at their convenience while others who required translation of English were given assistance.

The third stage was to conduct follow up interviews on information that was incomplete and/ or contradictory. Eight interviews of this nature were conducted. SPSS 22 was employed to run descriptive statistics, Pearson correlations, normality test and multiple regression. Pearson correlation was utilised to examine the relationships of the study variables while multiple regression and stepwise regression were employed to examine the prediction power of the variables. The captured interview extracts were logically organised into themes in order to identify and compare patterns in the interview data henceforth the qualitative data helped to enrich the quantitative data.

\subsection{Measuring and interpreting financial literacy}

Huston [14] highlighted the problem of a standardised measure of financial literacy by analysing 71 financial literacy studies and identified three main barriers:

1. Lack of a general consensus on definition of financial literacy;

2. Measures of financial literacy that are not comprehensive, and

3. Lack of a guide for interpreting this measurement to interpret financial literacy.

These limitations have been addressed by adopting the rule of thumb that the minimum number of items having meaningful leadings in a domain factor varies from 3 to 5 . In this survey, there are four financial literacy content areas, namely: knowledge, attitude, behaviour and systems. The twenty-one items used to assess financial literacy are thus adequate. Attention to item wording and ordering were also considered critical.

\subsection{Measuring and interpreting livelihood}

The measure of livelihood includes eight subcomponents and one aggregate measure based on availability, accessibility, quality, use, status of basic elements of livelihood. The eight are elements of livelihood are income and assets, food and nutrition, education, water, sanitation, health. The components of livelihood can be grouped into economic, security, food security, healthy security, education and empowerment. Livelihood had 30 items, by the rule of the thumb as mentioned earlier the number of items therefore were construed adequate.

\section{Results and Discussion}

This section presents and interprets results that were collected from one hundred and ninety-six respondents to examine the influence of financial 
literacy on livelihoods as mediated by financial systems.

The research was set to test the following Hypothesis that was based on the analytical framework shown in Figure 2.

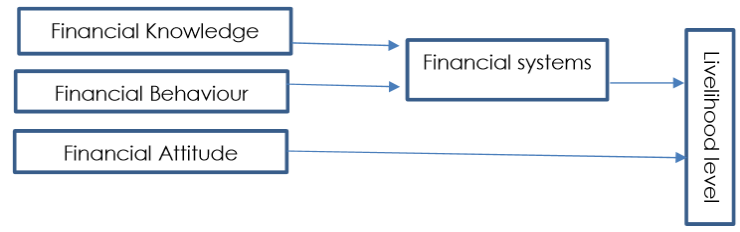

Figure 2. Analytical framework for Finance literacy and livelihoods

Based on Figure 2, the following Hypothesis are tested.

1. There is a relationship between financial knowledge and financial systems.

2. There is a relationship between financial behaviour and financial systems.

3. There is a relationship between financial attitude and one's livelihood level.

4. There is a mediating effect of financial systems on the relationship between financial Knowledge and livelihood level.

5. There is a mediating effect of financial systems on the relationship between financial behaviour and livelihood level.

6. There is a relationship between financial systems and livelihood level.

\subsection{Descriptive statistics on financial knowledge}

The respondents were asked to evaluate their level of financial knowledge on a Likert scale ranging from 5 (strongly agree) to 1 (strongly disagree). The average mean scores below 3 is interpreted to mean low financial knowledge; a score above 3 to 4 as moderate; while that above 4 as high level of financial knowledge.

A grand mean of 2.49 indicates an overall moderate financial knowledge. A critical analysis of the components of financial knowledge indicated that knowledge of monthly expenses, financial risks and insurance options is fairly high with the average mean score above 2.75. However, knowledge of getting and repaying a loan, financial plans and budgets, institutions that provide finance and investment options scored low with an average score below 2.23. Interviews with leaders revealed that many people didn't know the implications of taking loans. Indeed, one leader at the parish said; "we simply send what we have, having a budget that you follow as you spend will make people brand you mean". One leader reiterated that even those who have studied budgeting don't do it. When asked during the interviews about how much money is spent or generated on running the activities of the home every month, many respondents were ignorant.

\subsection{Descriptive statistics on financial}

The research findings indicate that the financial policies and procedures used by individuals and units to allocate risk and resources and exercise financial control and accountability are not so effective, not harmonised and inadequate in a number of aspects. This is illustrated by a grand mean of 2.18.

At the individual level, respondents were asked whether they had a system of tracking expenses, savings and investments and none of the respondents had anything. At the parish unit level, responses of leaders from the church indicate that the documentation policies and procedures are somehow explained; but the reporting and internal control procedures have a number of gaps. During the interview discussions, one respondent explained: "this parish has no approved financial system or procedure, it is based on the operating culture and trust. There is no asset register and it not clear which assets and projects belong to the diocese and which ones belong to the parish". It was noted that in all the parishes, manual income and expenditure systems were being used. Also, budget performance reports were hardly generated. One respondent explained that: since there is no approved financial system there are occasions when the parish priest overrules the decisions of the parish council. On how the parish ensured that the resources of the parish are safe, some respondents mentioned that once they are in the custody of the parish priest, they know it is safe. The Parish Priest is supported by the Treasurer, head of the Laity and Executive Committee. Some respondents indicated that periodically they receive reports from the finance committee and that there are some controls in place. Another mentioned that they also have a security guard.

\subsection{Descriptive statistics on financial attitude}

Respondents were asked to assess whether they have a positive or negative attitude on the following: basing on the budget to spend, commitment to saving a portion of their income; investing to generate a return, acquisition and loan repayment, and saving for retirement. When respondents were segmented into those with leadership roles and those without, the results indicated that the financial attitude of leaders is moderately high with a grand mean of 3.1, while the grand mean of respondents with no leadership roles was as low as 2.1. This implies that leaders' have a moderately positive psychological tendency that agrees to adopt effective financial practices. This is not the case with respondents who did not have leadership roles. In a follow-up 
interview, one respondent lamented thus: "whether you have a negative financial mind-set or not, money will not be got. Attitudes don't create money".

\subsection{Descriptive statistics on financial behaviour}

The study assessed the degree to which respondents portrayed appropriate financial behaviour on spending based on budgets, saving a percentage of income earned, having multiple investments generating returns, effective management of loans, having a fund to cater for old age, and having an insurance scheme. Again, the results of those without and those without leadership roles were segmented the findings results indicate that leaders moderately portray appropriate financial behaviour with an overall mean of 2.97 . The score for those with no leadership roles was 1.8 which is very low implying that majority of respondents portray inappropriate financial behaviour.

Descriptive statistics on livelihood levels The ability of respondents to satisfy their basic needs namely; food, shelter, clothing, sanitation, education and health care; among others were assessed and segmentation of respondents was made on having leadership roles. Findings for respondents with leadership roles indicated a moderately high livelihood level with a grand mean of 3.01. Since the livelihood levels of those with leadership roles are high, they can act as role models and mentors in financial literacy and livelihood improvement campaigns. The results of respondents with no leadership roles showed a grand mean of 2. 25 . Outstandingly low scores were indicated on medical treatment, insurance facilities, housing, diet, and food supply. This indicates that livelihood levels of respondents were very low.

During the data collection visits to the sampled household, there were clear indicators of low livelihood levels. Many respondents lamented about the high number of dependants. Indeed, the descriptive statistics of respondents indicate that $48 \%$ of the total respondents have more than three dependants staying with them. Also, there are respondents living on one meal day $(61 \%)$, poor housing facilities (69\%), unemployed (54\%), and lack clean and safe water within a radius of 5 kilometres $(62 \%)$.

In a discussion with some leaders on how they contribute to improving the livelihood levels of the people in their community, most respondents indicated that their contribution is minimal. Many respondents affiliated to the Catholic Church explained that the Church has Caritas as its development arm but in most of the Parishes visited, much as some have a Caritas volunteer at the Parish Councils, Caritas works more with beneficiaries than
Parishes. The Parish relevancy under Caritas services is not strong enough.

\subsection{Regressional Analysis of Financial Literacy And Livelihoods}

After descriptive analysis, the regression analysis was conducted to analyse the influence of financial literacy on livelihoods. The regression analysis was conducted to examine the influence of financial literacy on livelihood levels. The results show a combination of financial knowledge, attitude, behaviour, and systems influencing the level of livelihoods as indicated in table 1 . These variables can significantly explain $14 \%$ of the variance in levels of livelihood (Adj. R Square =.140; Sig 0.007). Meaning that a change in the literacy level will lead to a change in livelihood levels.

Apart from the overall effect of financial literacy on livelihood levels, the effect of financial knowledge, behaviour, attitude, and systems was tested. The results of the hypothesis test are summarised in Table 2.

It was established that there was no significant relationship between financial knowledge and livelihood levels (Beta=-0.147, Sig=0.335). Thus, the hypothesis was rejected. This implies that an improvement in financial knowledge may not necessarily improve livelihood levels. These findings are in agreement with those of Rajna et al. [35] who concluded that high levels financial literacy don't translate into an improvement in the livelihood levels.

Also, the findings indicate no significant relationship between financial behaviour and livelihood levels (beta $=-0.153$, sig $=0.330$ ). Thus, the hypothesis was rejected. This implies that an improvement in financial knowledge may not necessarily improve livelihood levels. This agrees with the finding on Potrich et al. [33].

The results indicated that Financial attitudes significantly predicts livelihood levels (Beta $=0.498$, sig=0.000). This implies that for livelihood levels to improve a positive financial attitude should be developed. The findings are supported by those of Potrich and et al. [33].

Generally, Financial attitudes significantly predicts livelihood levels (Beta $=0.498$, sig $=0.000$ while financial knowledge (Beta=-0.147, Sig=0.335), financial systems $(\mathrm{Beta}=-0.264, \mathrm{Sig}=0.138)$, and financial behaviour (beta $=-0.153$, sig $=0.330$ ) do not predict livelihood levels. This implies that for livelihood levels to improve a positive financial attitude should be developed.

The mediation effect of financial systems on financial knowledge, attitude, behaviour and livelihoods. Inspired by the results in Table 2, the researchers challenged themselves to examine whether financial systems mediate the relationship 
Table 1. Regression analysis of financial literacy and livelihood levels

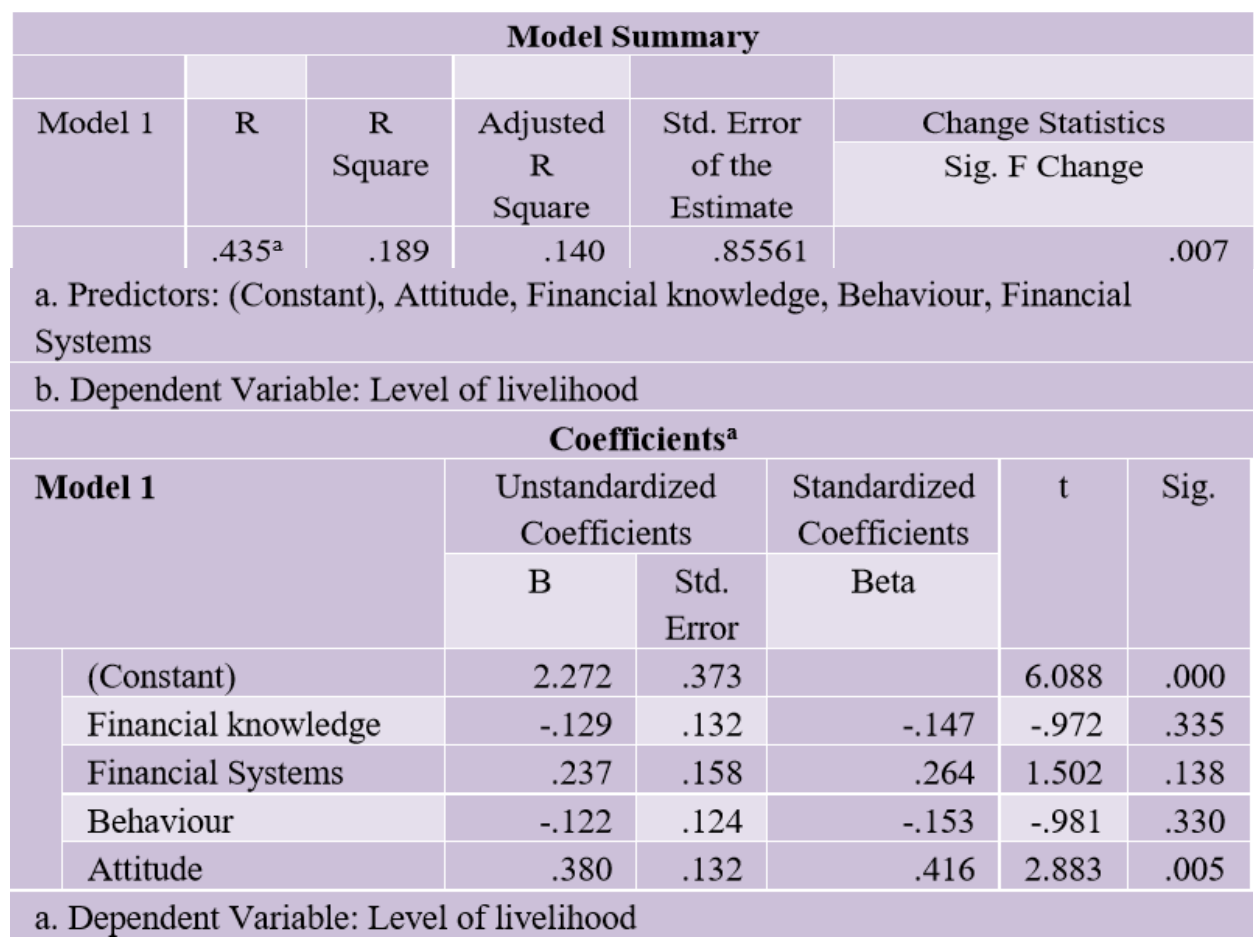

Table 2. Summary of Hypothesis testing

\begin{tabular}{|l|l|l|l|l|l|}
\hline Hypothesis & B & Beta & $\begin{array}{l}\text { Sig } \\
\text { value }\end{array}$ & $\begin{array}{l}\text { Hypothesis } \\
\text { supported? }\end{array}$ \\
\hline $\mathbf{1}$ & $\begin{array}{l}\text { There is a significant relationship between } \\
\text { Financial knowledge and Livelihood }\end{array}$ & -0.129 & -0.147 & 0.014 & rejected \\
\hline $\mathbf{2}$ & $\begin{array}{l}\text { There is a significant relationship between } \\
\text { Financial behaviour and Livelihood }\end{array}$ & -0.122 & -0.153 & 0.330 & rejected \\
\hline $\mathbf{3}$ & $\begin{array}{l}\text { There is a significant relationship between } \\
\text { Financial attitude and Livelihood }\end{array}$ & 0.380 & 0.416 & 0.005 & accepted \\
\hline $\mathbf{4}$ & $\begin{array}{l}\text { There is a significant relationship between } \\
\text { Financial systems and Livelihood }\end{array}$ & 0.262 & 0.291 & 0.014 & accepted \\
\hline $\mathbf{5}$ & $\begin{array}{l}\text { There is a significant relationship between } \\
\text { Financial knowledge and financial systems } \\
\text { There is a significant relationship between } \\
\text { Financial behaviour and financial systems }\end{array}$ & 0.461 & 0.473 & 0.000 & accepted \\
\hline $\mathbf{6}$ & 0.439 & 0.000 & accepted \\
\hline
\end{tabular}

Table 3. Summary of hypothesis testing for mediation

\begin{tabular}{|c|c|c|c|c|c|}
\hline & Hypothesis & $\begin{array}{l}\text { Path } \\
\text { coefficient }\end{array}$ & $\begin{array}{l}\text { Sobel Z- } \\
\text { Value }\end{array}$ & P-value & $\begin{array}{l}\text { Hypothesis } \\
\text { supported? }\end{array}$ \\
\hline 7 & $\begin{array}{l}\text { There is a mediation effect of } \\
\text { systems on the link between } \\
\text { financial knowledge and livelihood }\end{array}$ & 0.31 & 2.35 & 0.011 & supported \\
\hline 8 & $\begin{array}{l}\text { There is a mediation effect of } \\
\text { systems on the link between } \\
\text { financial behaviour and livelihood }\end{array}$ & 0.32 & 2.39 & 0.002 & supported \\
\hline 9 & $\begin{array}{l}\text { There is a mediation effect of } \\
\text { systems on the link between } \\
\text { financial attitude and livelihood }\end{array}$ & 0.27 & 1.24 & 0.34 & rejected \\
\hline
\end{tabular}


between financial knowledge, attitude, behaviour and livelihood levels. To carry out the mediation test, the conditions for mediation according to Baron and Kerry [44] were used. All the three conditions for mediation were met and consequently the Sobel mediation tests were run. The summary of the findings and the effects on the hypothesis are summarised in Table 3.

When the mediation tests were conducted, it was clear that financial systems mediate the relationship of financial knowledge and behaviour and livelihoods. Thus, financial behaviour and knowledge can significantly explain $41.6 \%$ of the variance in effectiveness of a financial system (Adj. $\mathrm{R}$ Square $=0.408$; Sig 0.000). Generally, the effectiveness of a financial system plays a key role in influencing the financial livelihood levels. Interestingly, the relationship between financial attitude and livelihoods is not mediated by financial systems. This implies that with a positive financial attitude, one's livelihood can be enhanced.

\section{Conclusions}

The study set out to examine the influence of financial literacy on the livelihoods of the people in the central region of Uganda. A critical analysis of financial knowledge, behaviour, attitude and systems on livelihood levels using regression and Sovel Zstatistic has generated key revelations. Outstandingly is that focusing on financial knowledge will not enhance people's livelihood levels. Secondly, for financial knowledge and behaviour to enhance livelihoods, financial systems should be developed and applied. Finally, financial attitude as a dimension of financial literacy is critical in livelihood enhancement.

\section{Recommendations}

Appropriate financial systems like record keeping, reporting and accountabilities should be instituted and adhered to if financial knowledge and behaviour are to enhance livelihoods. Improving the financial attitude of people should be a key focus for financial literacy trainers if livelihoods participants are to be enhanced. This required a major change in the training pedagogy. Thus, trainers should centre more on action based and experiential learning pedagogies.

\section{References}

[1] Abhisek Mishra. 2016. "Financial Literacy; A prelude to livelihood security", International Journal of Advancements in Research and Technology; Vol. 5 (1), Science Research Publishers.
[2] Achar, A., 2012. Saving and Investment Behaviour of Teachers. An empirical study. International Journal of Physical and Social Sciences. Vol 3 Issue 2 pp 263-286.

[3] Atkinson A., and Messy, F., 2012. "Measuring financial literacy": results of the OECD / International Network on Financial Education (INFE) Pilot Study [Working Paper n. 15].

[4] Bandura, A. 1989. "Perceived Self-Efficacy in the Exercise of Control Over AIDS Infection". In Primary prevention of AIDS: Psychological approaches, edited by Vickie M., Mays and George Albee, Newbury Park, CA: Sage Pub.

[5] Baron, R. M., and Kenny, D. A. 1986. "The moderatormediator variable distinction in social psychological research: Conceptual, strategic, and statistical considerations". Journal of Personality and Social Psychology, 51, 1173-1182.

[6] Brown, M., and Graf, R. 2013. Financial literacy and retirement planning in Switzerland. Numeracy6(2), art. 6.

[7] Chambers, R., and Conway, G. 1992. "Substantial rural Livelihoods: practical concepts for the 21st century", Discussion paper 296, Brighton, U.K., Institute of Development Studies.

[8] Cole S, and Fernando N. 2008. "Assessing the Importance of Financial Literacy," ADB Finance for the Poor, Volume 9 (2).

[9] Cronbach L. J. 1951. Coefficient alpha and the internal structure of tests. Psychometrika, 16 (3), 297-334.

[10] Dinga E, Pop N, Dimitrui M, Milea C. 2011, "Modelling Financial Behaviour of a population", Romanian Journal Of Economic Forecasting, 13(1) 239254.

[11] European Commission. 2007. Survey of Financial Literacy Schemes in the EU27. Retrieved March 5, 2017, from

http://ec.europa.eu/finance/finservicesretail/docs/capability /report_survey_en.pdf

[12] Frankenberger,T. 1996. "Measuring household livelihood security: an approach for reducing absolute poverty", Food forum, No. 34, Washington, DC. USA.

[13] Godwin, D. D. and Carroll, D. D. 1986. "Financial management attitudes and behavior of husbands and wives". Journal of Consumer Studies and Home Economics, 10, 77-96.

[14] Huston S J. 2010. "Measuring financial literacy". The Journal of Consumer Affairs. 44(2), 296-316. IFRC International Federation of the Red Cross and Red Crescent Societies 2017. - www.ifrc.org

[15] Jorgensen B.L. 2007. "Financial Literacy of College Students: Parental and Peer Influences." Unpublished Master Thesis. Virginia Polytechnic Institute and State University: Virginia. 
[16] Kalyanwala S, and Sebstad, J. 2006. Spending, saving, and borrowing: Perceptions and experiences of girls in Gujarat. New Delhi: Population Council.

[17] Kamukama E. 2017. "How youth perceive Money", Daily Monitor, Tuesday August 15th, pp 24

[18] Kasekende L., 2015. Improving financial literacy in Uganda Literacy Information Sharing Group (FLISG)

[19] Klapper L., Lusard A. and Oudheusden. 2016. Financial Literacy around the World. http://www.FinLit.MHFT.com

[20] Krechvoska Michaela. 2015. Financial Literacy as a path to sustainability; Trandy V Podnikani, 5 (2) 3 - 12; UWB.

[21] Likert, R. 1931. A technique for the measurement of attitudes. Archives of Psychology. New York: Columbia University Press.

[22] Lindenberg, 2002. "Measuring household livelihood security at family and community level in the Developing world", Word Development, 30(2) 301-318, Elsevier Science Ltd.

[23] Mandell, L. 1997. Personal financial survey of high school seniors. Washington, D.C.: Jump Start Coalition for Personal Financial Literacy.

[24] Maslow, A. H. 1943. "A theory of Human motivation”, Psychological Review, 50(40), 370-396.

[25] Messy F, Monticone C. 2012. - The Status of Financial Education in Africall, OECD Working Papers on Finance, Insurance and Private Pensions, No. 25, OECD Publishing, available

http://dx.doi.org/10.1787/5k94cqqx90wl-en p. 25.

[26] Mutebile E. 2015. "Bank of Uganda in financial literacy drive", New Vision November, 12th 2015.

[27] Noctor M, Stoney S, and Stradling R. 1992. Financial Literacy: A Discussion of Concepts and Competences of Financial Literacy and Opportunities for its Introduction into Young People's Learning. Report prepared for the National Westminster Bank, London: National Foundation for Education Research.

[28] Norvilitis J M, and MacLean M G. 2010. The role of parents in college students' financial behaviors and attitudes. Journal of Economic Psychology 31(1), 55-63.

[29] Organisation for Economic Co-Operation and Development .OECD. 2013. Financial literacy and inclusion: Results of OECD/INFE survey across countries and by gender. OECD Centre, Paris, France.

[30] Oseifuah Emmanuel Kojo. 2010. "Financial Literacy and Youth entrepreneurship in South Africa, African Journal of Economic and Management studies Vol.1 (2), Emerald Group.

[31] Ozmete E. and Hira T. 2011. "Conceptual analysis of Behavioural Theories / Models: Application to Financial
Behaviour; European Journal of Social Sciences 18(3): 386 -404 .

[32] Parrotta J.L.andPhyilis J.J. 1998. "The Impact of Financial Attitude and Knowledge on Financial Management and Satisfaction of Recently Married Individuals", Association for Finance Counselling and Planning Education

[33] Potrich A. C., Vieira K.M. and Kirch G. 2015. "Determinants of Financial Literacy: An analysis of the influence of Socioeconomic and Demographic Variables", Accounting and Financial Review Journal, 26(9); 52 - 64.

[34] PSFU (2016); Annual Report, Kampala Uganda.

[35] Rajna A., Sharifah W. P., Junid, M. H. 2011. Financial Management Attitude and Practice in Public and Private Medical Service in Malaysia; International Journal of Business and Management vol. 6 (8) pp. 105-113. Canadian Centre of Science and Education.

[36] Refera M. K., Dhaliwal N. K., Kaur J. 2016. "Financial literacy for developing countries in Africa", A review of concept, significance and research opportunities", Journal of African Studies and Development, 8(11)1-12.

[37] Sean Wise 2013. "The Impact of Financial Literacy on New Venture Survival"; International Journal of Business Management, Vol. 8(23), Canadian Centre of Science and Education.

[38] Sebstad, J., Cohen, M. and Nelson, C. 2015. "Building Financial Capabilities for Financial Inclusion: Views Of Low-Income Communities," Washington, DC: Microfinance Opportunities.

[39] Stuart, G., Ferguson M., and Cohen, M. (2011). Cash In, Cash Out: Financial Transactions and Access to Finance in Malawi. Washington, DC: Microfinance Opportunities.

[40] Tavako, M. and Dennick R. 2011. "Making sense of Cronbach's Alpha", International Journal of Medical Education, 2(6), 53-55.

[41] Uganda Bureau of Statistics. 2016. The National Population and Housing Census 2014 - Main Report, Kampala, Uganda.

[42] World Bank 2017. Global financial development report: financial inclusion Report. Washington DC.

[43] Yaghmale 2003; "Content validity and its estimation); Journal of Medical Education 3(1) 25 - 27.

[44] Baron, R.M., Kenny, D.A., (1986). The moderatormediator distinction in social psychological research: Conceptual, strategic, and statistical considerations, Journal of Personality and Social Psychology, 51, 11731182 . 